\title{
O trabalho com narrativas audiovisuais no ensino de Libras como L2 para ouvintes
}

\author{
Aryane Nogueira ${ }^{1}$ \\ Janaina Cabello ${ }^{2}$
}

\section{Resumo}

O presente trabalho tem como objetivo trazer o relato de experiência das autoras no que se refere a situações de ensino de Libras como L2 para alunos ouvintes, tendo como proposta pedagógica, fundamentada em uma abordagem de ensino de língua comunicativa, a elaboração de narrativas audiovisuais pelos alunos participantes de cursos de Libras. Considerando que os estudos sobre metodologias para o ensino de língua de sinais ainda são em pequeno número, a intenção é contribuir para a área de metodologias e estratégias de ensino, sobretudo no que se refere ao ensino-aprendizado de Libras como segunda língua para/por alunos ouvintes.

Palavras-chave: ensino de Libras; segunda língua; narrativas; vídeos; alunos ouvintes

${ }^{1}$ Professora doutora do Departamento de Psicologia Educacional da Faculdade de Educação da Universidade Estadual de Campinas. E- mail: aryane@unicamp.br

2 Professora mestra do Departamento de Psicologia, no curso Bacharelado em Tradução e Interpretação em Libras/Língua Portuguesa - Universidade Federal de São Carlos. Doutoranda na Faculdade de Educação - UNICAMP. E-mail: janainacabello@ufscar.br 


\begin{abstract}
The aim of this work is to bring a description of the authors experiences in relation to situations when Brazilian Sign Language (Libras) is taught as L2 to hearing students, with the pedagogical proposal of developing audiovisual narratives by students of Libras courses, based on a communicative language teaching approach. Considering that the number of studies on methods to teach sign language is still small, the intention is to bring a contribution to the sector of teaching methodologies and strategies, particularly with regard to teaching-learning Libras as a second language to/by hearing students.
\end{abstract}

Keywords: Libras teaching; second language; narratives; videos; hearing students

\title{
Introdução
}

A disciplina de Língua Brasileira de Sinais (Libras) nos cursos de graduação teve uma grande expansão a partir da Lei 10.436 de 2002 (BRASIL, 2002), que reconhece a Libras como língua oficial do país, e do Decreto 5.626 (BRASIL, 2005), que a regulamenta e prevê a inserção do ensino de Libras como obrigatório nos cursos de licenciatura em Fonoaudiologia, Pedagogia e Educação Especial, e como disciplina optativa e/ou eletiva nos demais cursos de formação em nível superior (como já evidenciado por ALBRES, 2012; CAMPOS, 2014; LODI, 2014; SANTOS e CAMPOS, 2014; LEBEDEFF e SANTOS, 2014, dentre outros).

Uma das principais justificativas para a inserção obrigatória das disciplinas de Libras nos currículos de cursos de licenciatura e algumas graduações, de acordo com Caetano e Lacerda (2014), está na necessidade de formação de profissionais competentes para atuar em uma perspectiva 
inclusiva. No que se refere à inclusão no espaço escolar, no caso dos alunos surdos, dentre as barreiras para que esse processo ocorra, está o fato de o aluno surdo fazer uso de uma língua que é diferente da utilizada pela maioria na escola, incluindo os seus professores e colegas de sala. Portanto, formar profissionais aptos a atuar em uma perspectiva inclusiva na escola, por exemplo, requer a preparação de professores que consigam ao menos estabelecer uma comunicação básica com os alunos surdos (CAETANO e LACERDA, 2014).

Além do foco na comunicação, espera-se que as disciplinas de Libras, sobremaneira nas licenciaturas, envolvam formação para conhecimentos a respeito de metodologias e elaboração de aulas para alunos surdos, incluindo estratégias e vocabulário específicos para os diferentes conteúdos (CAETANO e LACERDA, 2014).

A importância do que expõem Caetano e Lacerda (2014), sobre a responsabilidade de formação para a heterogeneidade que a disciplina de Libras carrega, esbarra na preocupação em relação aos diferentes modelos e metodologias que têm sido adotados, ainda sem muitas reflexões, pelo necessário cumprimento da legislação que estabelece a obrigatoriedade de oferecimento da disciplina. A esse respeito, Santos e Campos (2014) salientam que a forma como as disciplinas de Libras vêm sendo organizadas espelham a falta de orientações mais definidas em relação aos seus objetivos e às necessidades formativas dos alunos, pela pressa com que se procurou cumprir as exigências legais de oferta do curso de Libras para o ensino superior.

Sendo assim, apesar da expansão do oferecimento da disciplina de Libras - o que também demanda um aumento no número de profissionais para o ensino da língua e de materiais didáticos para esse fim, como apontado por Albres (2012) -, percebe-se que as questões metodológicas para o ensino dessa língua ainda são um impasse entre os educadores, já que os materiais e a literatura continuam escassos no que diz respeito ao ensino e aprendizado de Libras por alunos ouvintes 
(PEREIRA, 2009; GESSER, 2010; ALBRES, 2012; NEVES, 2012, dentre outros).

Além das dificuldades em relação aos métodos de ensino adotados, Pereira (2009) salienta que ainda são poucos os trabalhos que têm como foco o ensino-aprendizagem da língua de sinais como L2 para ouvintes, enfatizando, contudo, que "existe certa urgência nesses estudos, tendo em vista [...] a propagação, sem precedentes, dos cursos de Libras" (PEREIRA, 2009, p. 1).

O objetivo deste artigo, portanto, é trazer o relato de experiência das autoras no que se refere a situações de ensino de Libras como L2 para alunos ouvintes. Como se observa uma lacuna em relação ao estudo dessa temática, a intenção é que as reflexões aqui estabelecidas possam contribuir para a área de metodologias e estratégias de ensino de língua de sinais, sobretudo no que se refere ao ensino-aprendizado de Libras como segunda língua para/por alunos ouvintes. A proposta de elaboração de narrativas audiovisuais pelos alunos participantes de cursos de Libras, fundamentada em uma abordagem de ensino de língua na perspectiva comunicativa, foi uma das atividades realizadas na experiência aqui focalizada, e é ela que será explorada mais adiante.

O uso de vídeo em situações de ensino de Libras para alunos ouvintes em uma abordagem comunicativa também já foi temática explorada no trabalho de Lebedeff e Santos (2014). A proposta de produção de vídeos das autoras pretendia distanciar-se de um ensino focado apenas nos elementos lexicais, mostrando-se válido, uma vez que, como as próprias autoras destacam, esse tipo de material pode ser aproveitado tanto no ensino de Libras presencial como a distância. No entanto, enquanto essa experiência apresentou aos alunos materiais fílmicos prontos (elaborados por docentes), em nosso trabalho são os próprios alunos que, por meio da produção dos materiais em vídeo, envolveram-se em práticas sociais de linguagem que ainda tiveram impacto nas representações (LEBEDEFF e SANTOS, 2014) sobre surdez, surdos e a Libras. 
Passaremos, portanto, a uma breve apresentação da abordagem comunicativa de ensino e, em seguida, ao relato e análise da experiência de utilização da atividade de narrativa em vídeo.

\section{Abordagem comunicativa e o ensino de Libras como L2 para ouvintes}

A abordagem comunicativa para o ensino de línguas estrangeiras ou segundas línguas, de acordo com Martinez (2009, p. 65), teve sua origem a partir de uma demanda política e institucional da Europa, em virtude do interesse de construção da Comunidade Europeia. Naquele momento, ensinar uma língua significava desenvolver no aprendiz um nível mínimo com o qual ele poderia agir linguisticamente, de acordo com seus objetivos e contextos específicos.

A importância desse movimento está na abertura de possibilidades para o que Martinez (2009, p. 68) define como uma renovação pedagógica, uma vez que, a partir daí, há uma modificação significativa no sentido atribuído à indagação sobre o que seria saber uma língua. Com o advento dessa abordagem nos anos de 1970, o ensino-aprendizagem de língua estrangeira, em vez de assentar-se sobre a ideia de que aprender uma nova língua consiste basicamente no processo de formação de um novo hábito mecânico, passou a ser visto como produto da interação significativa entre estudantes e usuários da língua-alvo, como resultado da criação colaborativa.

A noção de língua(gem) que se tem na abordagem comunicativa, conforme Martinez (2009, p. 67), é que ela é "[...] um meio de agir sobre o real [...]". As formas linguísticas que a constituem têm seus sentidos construídos de maneira partilhada, e os usos desses recursos linguísticos acabam por adquirir funções diferentes, a depender dos usos que são feitos e pelas intenções dos enunciadores em eventos de comunicação que 
são considerados complexos, pois são constituídos a partir de diferentes atos, sequências e trocas.

Considerando o anteriormente exposto, o aprendiz de uma segunda língua ou de uma língua estrangeira, numa lógica comunicativa, é aquele que terá que lidar com a complexidade do evento de comunicação e, na medida em que precisa responder a uma determinada intenção enunciativa, lança mão de: a) determinadas capacidades linguísticas, e; b) determinados conteúdos semânticos, nunca deslocados dos contextos nos quais a atividade discursiva se insere. Tem-se, portanto, na abordagem comunicativa, uma perspectiva mais integrativa das capacidades e dos conteúdos linguísticos para que o aprendiz venha a desenvolver suas competências comunicativas. Isso significa que, como explica Martinez (2009, p. 68-69), além de conhecer o sistema linguístico, o aprendiz precisa desenvolver conhecimentos que o possibilitem usar esse sistema de maneira adequada, a depender da situação de enunciação e de um determinado contexto social.

Albres (2012) explica que a abordagem comunicativa - na qual é necessário que o estudante adquira ao menos duas competências, ou seja, "a competência gramatical (conhecimento da estrutura de uma língua: fonologia, morfologia, sintaxe) e a competência comunicativa (conhecimento do uso da língua em situações reais de comunicação: graus de formalidade, diferentes gêneros textuais etc.)" (ALBRES, 2012,p. 128), é uma perspectiva predominante atualmente no ensino de língua estrangeira. No entanto, pensando especificamente no ensino de Libras, a autora ressalta que é necessário ter prudência ao aplicar métodos primeiramente desenvolvidos para línguas orais-auditivas no ensino de línguas de sinais, pela diferença de modalidade entre essas línguas.

Para Albres (2012), essa abordagem não é ainda a tendência observada para o ensino da Libras, visto que, como menciona a autora, um dos materiais didáticos amplamente adotados para o ensino da língua apresenta um método que "focaliza unicamente o ensino da gramática, 
preterindo, ou mesmo ignorando, o seu uso em situações reais de comunicação" (ALBRES, 2012, p. 128).

Acreditamos ser importante destacar ainda que, no ensino de Libras, também é prática comum, tal como afirma Neves (2012), a ênfase no ensino de vocabulário de modo descontextualizado (através dos conjuntos chamados sinalários) - seja em cursos livres ou disciplinas oferecidas dentro de cursos de graduação -, sendo que aspectos como o uso gramatical do corpo e das expressões faciais são negligenciados, o que é bastante problemático no caso da Libras, que se constitui como uma língua visual-espacial e que tem dentro de seus parâmetros formacionais e de suas convenções linguísticas o uso do corpo e das expressões faciais para marcar, por exemplo, a entoação, os referentes, mudanças de turno, dentre outros aspectos. Dessa forma, destacamos das reflexões de Neves (2012), que

a maioria dos cursos de LIBRAS, além de não lançar mão de nenhuma metodologia específica, em geral, ignorava características da gramática da LIBRAS [...]. Nada ou pouco se explicava (e ainda se explica) sobre o papel da iconicidade, da simultaneidade e do uso de expressões faciais [...]. Isso se reflete nos poucos materiais didáticos desenvolvidos para o ensino de LIBRAS que, em geral, trabalham vocabulário e estruturas gramaticais descontextualizados (NEVES, 2012, p. 1-2).

A nossa busca pela abordagem comunicativa vem, portanto, do necessário distanciamento de modelos de ensino pautados somente nos aspectos gramaticas ou no vocabulário de maneira compartimentalizada, e que não possibilitam ao aluno o aprendizado da língua de sinais por meio de vivências de uso da língua como um todo. Sobre essa abordagem, Gesser (2010, p. 29-30) explica que o seu eixo central está alicerçado na ideia de que a língua a ser ensinada serve para comunicar e interagir, havendo uma preocupação em trabalhar as necessidades do aluno de maneira que o aprendizado se dê de forma colaborativa, interativa e baseada em tarefas 
que se aproximam ao uso real da língua ${ }^{3}$. As atividades estão centradas no conteúdo, sendo este o guia das formas e sequências linguísticas a serem apresentadas/utilizadas. Isso não significa que a língua é ensinada por partes, pois, como a ênfase está em contextos e situações reais de seu uso, as atividades são conduzidas a partir do todo da língua.

No livro "O ouvinte e a surdez: sobre ensinar e aprender a Libras", Gesser (2012) traz contribuições importantes sobre a metodologia comunicativa aplicada ao ensino de Libras para alunos ouvintes. Os exemplos de atividades apresentados e discutidos pela autora auxiliam na compreensão de que o ensino de Libras, nesta perspectiva, deve ser pensado a partir de uma outra (nova) lógica de organização e percepção do que é a língua de sinais, de qual seria o papel do professor que ensina essa língua e o papel do aprendiz.

Dessa forma, a Libras, numa abordagem comunicativa, já não pode ser mais vista apenas como um conjunto de estruturas e regras linguísticas a serem aprendidas, pois importa considerar que ela é um meio de agir, inclusive culturalmente, sobre a realidade. Apropriando-nos do que expõe Martinez (2009, p. 69) a respeito das quatro orientações da abordagem comunicativa, poderíamos pensar que ensinar Libras nesta perspectiva envolveria um retorno para a importância em se focalizar o sentido (1) no exercício da comunicação real ou o mais próxima do real

3 Gesser (2010, p. 31) chama a atenção para o fato de que, ao buscar práticas comunicativas mais próximas do real, o professor está, na verdade, fazendo tentativas e aproximações do real. Concordamos com a autora sobre a importância de se destacar esse aspecto, a fim de evitar o fortalecimento de mitos, como o de que a aprendizagem da língua só se daria se falássemos muito próximo aos nativos (mito do falante nativo), ou de que a união de vocábulos, como unidades transparentes, já seriam suficientes para estabelecer a comunicação (mito da comunicação). Acreditamos que o mito do falante nativo abordado por Gesser (2010) se relaciona diretamente com as reflexões de Carvalho (2016). Este autor propõe que, embora o ensino da Libras seja pautado nas reivindicações de que o modelo de ensino ideal seja o de um professor surdo, é possível um outro olhar no que diz respeito à docência da Libras, apontando que "não basta ser surdo para ensinar a Libras". Nesse sentido, o autor argumenta que "ser surdo não pode ser a ÚNICA condição para que o sujeito possa advogar para si o ensino de Libras" (CARVALHO, 2016, p. 10). 
(2), compreendendo que o aprendiz de Libras é o agente principal na sua aprendizagem (3), ou seja, um aprendiz ativo, comprometido com a comunicação e participante de situações de ensino nas quais os aspectos pragmáticos e sociais envolvidos no ato comunicativo são diretamente tomados como objetivo das aulas pelo professor (4).

Considerando o exposto, isto é, diante da obrigatoriedade do ensino de Libras nos cursos de graduação, e por compreendermos a necessidade de promover o ensino da língua comprometido com uma formação plena que não pretenda, nesse sentido, apenas atender a obrigatoriedade legal, mas oportunizar aos alunos a compreensão das questões linguísticas, sociais e políticas mais amplas no que se refere ao uso e circulação da Libras e sua expansão, apresentamos neste trabalho uma experiência de ensino de Libras como L2, na qual foi adotada a elaboração de narrativas audiovisuais como estratégia pedagógica, buscando a interação entre estudantes e a língua de sinais para a produção de discursos significativos em Libras.

\section{Narrativas em vídeo promovendo o ensino-aprendizado (em Libras) de aspectos linguísticos, sociais e políticos}

As disciplinas de Libras - das quais recortamos as atividades de vídeo analisadas neste artigo - foram oferecidas durante um semestre letivo, com a possibilidade para que alunos de diferentes cursos de graduação de uma universidade pública do interior do estado de São Paulo pudessem se matricular. Do total de 11 turmas disponíveis no semestre analisado, as autoras ficaram responsáveis por quatro delas, sendo que cada turma era composta por 20 alunos, de ambos os sexos, na faixa etária entre 18 e 34 anos, dos cursos de Biblioteconomia, Imagem e Som, Terapia Ocupacional, Engenharia de Materiais, Engenharia de Produção, Estatística, Física, Pedagogia, Matemática, Letras, Linguística e Gerontologia. Para os cursos 
de licenciatura em Física, Matemática, Letras e Pedagogia, a disciplina era obrigatória, sendo que os alunos dos demais cursos fizeram a escolha por estudar Libras como uma disciplina optativa a ser integrada em sua grade curricular obrigatória. A disciplina foi oferecida semanalmente, ao longo de 15 semanas, e cada aula teve a duração de aproximadamente duas horas.

A proposta pedagógica teve como objetivo convidar os alunos a produzir narrativas em Libras em formato de material audiovisual em dois momentos: no meio do semestre e como atividade de conclusão da disciplina. No primeiro vídeo, os alunos foram instigados a narrar sobre si mesmos (idade, onde nasceram, que curso frequentavam, contar um pouco sobre suas atividades de lazer, preferências pessoais etc.), sendo que a atividade poderia ser realizada individualmente ou em duplas. No segundo momento (mais ao final do semestre), para desenvolverem uma outra narrativa, foi proposto que os alunos refletissem sobre as possíveis relações entre a disciplina de Libras em suas formações nas diversas áreas. Nesse sentido, decidimos que as narrativas deveriam se ater às possibilidades de relação entre a Libras e as áreas específicas de formação e/ou na relevância da disciplina como experiência de formação profissional, por acreditarmos que tal proposta conjugaria os conhecimentos práticos da língua com as discussões de cunho mais teórico realizadas ao longo da disciplina e que envolveram, por exemplo, as temáticas do estatuto de língua da Libras, a oficialização e a legislação sobre língua de sinais no Brasil, identidades e culturas surdas, o aluno surdo na escola, entre outros. Os vídeos para o encerramento da disciplina poderiam ser realizados em duplas ou individualmente, deveriam apresentar uma duração que variasse entre três e dez minutos e, além da apresentação da história em Libras, os alunos poderiam agregar ao vídeo outros recursos, como imagens, texto escrito em português, sons, trechos de outros vídeos, isto é, demais recursos que considerassem pertinentes para compor a narrativa, que seria apresentada e discutida em sala posteriormente. 
Os alunos produziram e editaram seus próprios vídeos com os recursos disponíveis em seus aparelhos celulares ou através de recursos de webcam de seus computadores. Os vídeos foram disponibilizados para as docentes por e-mail, através de carregamento do vídeo no canal YouTube, em arquivos privados.

Além da produção dos vídeos, em pelo menos dois encontros que antecederam a data de entrega do material, as docentes solicitaram aos alunos que elaborassem seus roteiros de gravação em português escrito. O material escrito serviu de base para que, por meio de atividade de adaptação de trechos do roteiro em português escrito para a Libras, os alunos se engajassem no exercício metalinguístico e de análise contrastiva das duas línguas, salientando, na prática, a diferença de estruturação das duas línguas ${ }^{4}$.

Os critérios de avaliação da atividade envolveram, além dos aspectos gramaticais da Libras (uso do espaço, marcação temporal, presença de expressões faciais e corporais, a configuração de mão, movimento, orientação e ponto de articulação no momento da execução dos sinais (QUADROS e KARNOPP, 2004), o modo como os alunos exploraram os campos semânticos apresentados e discutidos ao longo das aulas e a construção de textos (narrativa, diálogos) em Libras.

Acreditamos que os exemplos que traremos a seguir ilustram bem nossas considerações a respeito das possibilidades do trabalho com a elaboração de vídeos para o ensino e aprendizagem da Libras como L2.

\section{O vídeo como possibilidade de construção de conhecimento linguístico sobre a Libras}

No ensino de Libras, assim como colocou Gesser (2012), o desenvolvimento de duas habilidades no aluno se fazem importantes: as

${ }^{4}$ Essa diferença já havia sido marcada pelas docentes, inclusive, por meio da leitura e apresentação de materiais teóricos. 
habilidades de expressão em sinais (sinalização) e de compreensão visual, que são competências de produção e recepção da língua de sinais, respectivamente. Nas atividades de narrativa em vídeo, acreditamos que ambas as habilidades foram colocadas em funcionamento: a habilidade de recepção da língua foi acionada nos momentos que antecederam a preparação do material em vídeo, pois, além das aulas terem sido realizadas prioritariamente na língua de sinais, a própria explicação da comanda da atividade e os momentos de produção de roteiros em português escrito, discussão e adaptação desses roteiros para Libras foram todos realizados em língua de sinais. Já a habilidade de produção pôde ser trabalhada e avaliada no próprio material em vídeo e, evidentemente, nos momentos de preparação do mesmo, quando os alunos tinham que explicar suas ideias ou esclarecer dúvidas, por exemplo.

Percebemos, no que se refere à habilidade de produção, que, ao elaborarem as narrativas em vídeo, os alunos puderam colocar em prática os conhecimentos linguísticos sobre a Libras adquiridos durante as aulas. Foi possível observar, inclusive, o desenvolvimento do aprendizado dos alunos, ao fazermos a análise comparativa dos vídeos produzidos no meio do semestre e ao final do semestre.

Dois materiais em vídeo, elaborados por alunos ${ }^{5}$ do curso de Imagem e Som, demonstram bem os aspectos levantados anteriormente. O primeiro vídeo, intitulado aqui de "Apresentação e Curso" (ver Fig. 1), produzido por uma dupla de alunos, teve como temática a apresentação de seus nomes, do curso que frequentavam e de suas preferências. Como os dois integrantes participavam do mesmo curso, eles aproveitaram para conversar sobre as atividades com as quais mais simpatizavam: televisão ou cinema. Um deles diz preferir um determinado tipo de programa televisivo, enquanto o outro fala sobre seu filme favorito. Ao final, eles se despedem, pois um deles precisa sair para a aula de Libras, enquanto o

5 Os alunos envolvidos autorizaram o uso de suas imagens através da assinatura de Termos de Consentimento Livre e Esclarecido. 
colega vai comer uma pizza. Há um convite para irem juntos comer pizza, mas o jovem nega, dizendo que está mesmo na hora de ir para a aula de Libras.
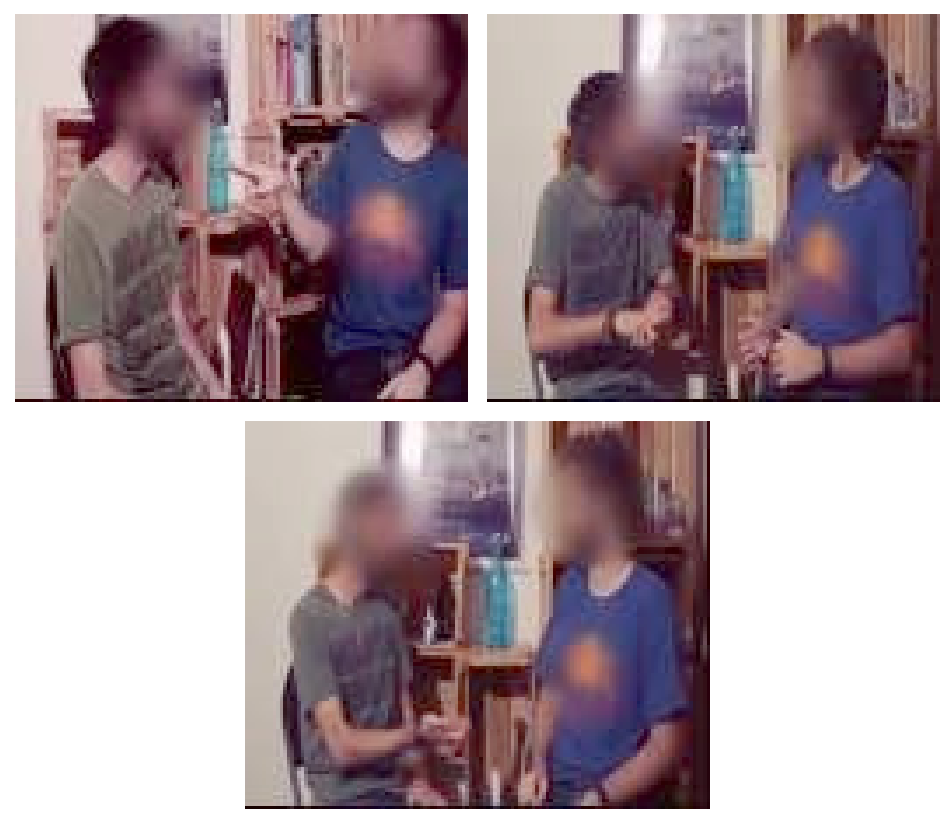

Figura 1. Trechos do vídeo "Apresentação e Curso". Da esquerda para a direita, realização de substantivo, advérbio e verbo.

Pela breve descrição do vídeo é possível perceber que os campos semânticos explorados pelos alunos foram variados - incluindo cumprimentos e formas de apresentação, profissões e áreas de formação, alimentação e mídias. Dentre os recursos linguísticos utilizados estão os sinais, o alfabeto manual e expressões faciais e corporais. Ainda não se observa, nesse material, o uso de classificadores ${ }^{6}$, no entanto, já aparecem

${ }^{6}$ É preciso considerar que o contato dos alunos com a língua de sinais era bastante recente. $\mathrm{Na}$ época de elaboração do video, havíamos realizado cerca de seis encontros. 
enunciados compostos por substantivos, verbos, adjetivos, advérbios, afirmações, negações e interrogativas (ver exemplos na Fig.1).

Como os alunos ainda estavam no meio do semestre e o primeiro contato deles com a Libras era por meio da disciplina, era esperado que os mesmos apresentassem dificuldades ou momentos em que seus enunciados em Libras se aproximassem mais da estrutura do português. Nesse primeiro vídeo, por exemplo, na situação em que eles estão se cumprimentando, há uma inversão na direção do movimento do sinal BOM (Fig. 2). Um dos participantes, inclusive, produz o sinal muito próximo à região do queixo se aproximando da realização do sinal HOMEM. Em outros momentos, como na apresentação do sinal ONDE para a pergunta “onde você nasceu?”, na apresentação do sinal de TELEVISÃO ou na apresentação do sinal GOSTAR para a afirmação "gosto do filme..." (Fig. 2), há imprecisão na realização dos movimentos desses sinais, mostrando que, embora os parâmetros de configuração de mão, localização, orientação e expressões não-manuais estivessem corretos, havia ainda uma assistematicidade no que se refere ao uso do parâmetro movimento $(\mathrm{M})$ em alguns sinais.
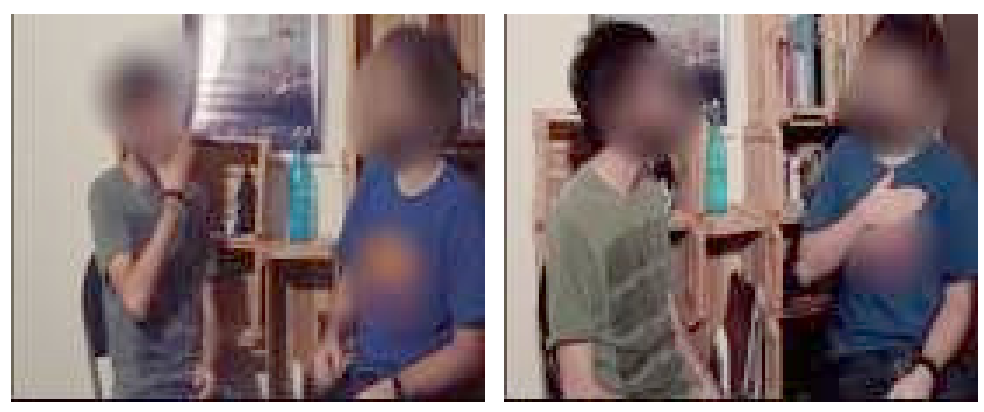

Figura 2. À esquerda, o aluno realiza o sinal BOM com inversão do movimento e, à direita, o aluno realiza sinal GOSTAR com movimento de batida intermitente no peito. 
Os próprios alunos mencionaram que a realização dos vídeos ajudou na percepção do modo como estavam construindo a sinalização e também fazendo uso das expressões faciais e corporais. Muitos deles relataram a necessidade de repetir a filmagem por várias vezes, pois se sentiam muito "duros" ou "parados" ao realizarem os enunciados na língua de sinais, por considerarem que estavam muito diferentes das formas de sinalizar com as quais eles já haviam tido contato durante as aulas. Foi possível perceber que a expressividade dos alunos apresentou uma considerável mudança após a realização desta atividade.

Como já explicitado anteriormente, ao final do semestre foi solicitado aos aprendizes que elaborassem mais um vídeo. Os cursistas de Imagem e Som optaram por trabalhar em grupo novamente, produzindo um vídeo que chamamos aqui de "Trabalho de Libras". Como a proposta era que os alunos articulassem o conteúdo aprendido na disciplina com as especificidades de cada curso de formação, o grupo optou por construir uma narrativa na qual um dos participantes precisava gravar um vídeo para um trabalho da disciplina de Libras e o outro participante era quem ajudava o colega com a elaboração do vídeo, ensinando-o aspectos referentes à produção de imagens em vídeo com qualidade. Sendo assim, como o material continha um vocabulário específico da área de fotografia, os alunos fizeram a opção por iniciá-lo com a apresentação de um pequeno glossário com os sinais que seriam utilizados ao longo da narrativa. Nesse momento, os vocábulos são apresentados por meio do alfabeto manual seguido do respectivo sinal, mais uma legenda em português (ver Fig. 3). 

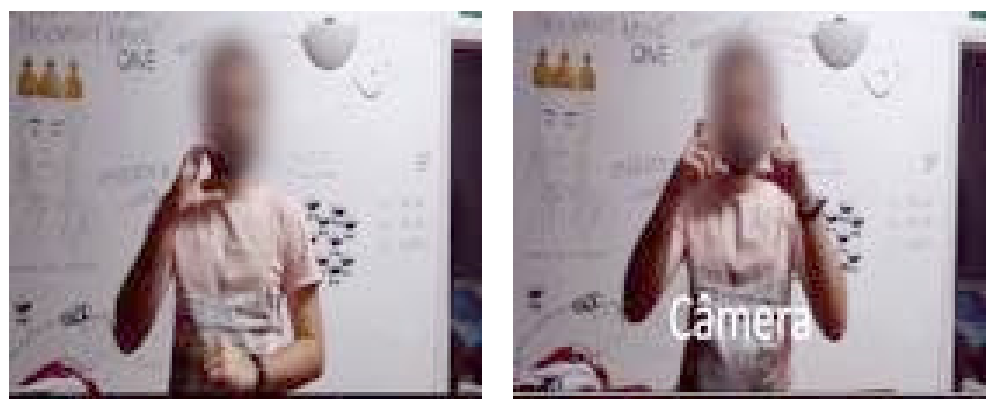

Figura 3. Glossário no início do vídeo "Trabalho de Libras": aluno realizando a soletração manual de C-Â-M-E-R-A (à esquerda) e sinal CÂMERA (à direita).

No vídeo "Trabalho de Libras", como mencionado, os diálogos apresentados giram em torno da necessidade de realização de um trabalho em vídeo para disciplina de Libras por um dos participantes. Ele é recebido por seu colega que, ao longo da narrativa, tenta dar dicas para que ele possa melhorar a produção de seu vídeo. A cada tentativa, uma nova dica é acrescentada - troca do equipamento de filmagem, uso de tripé, de iluminação (ver exemplo na Fig. 4) e do enquadramento adequado - até que, ao final, os dois participantes comemoram a realização satisfatória da tarefa.
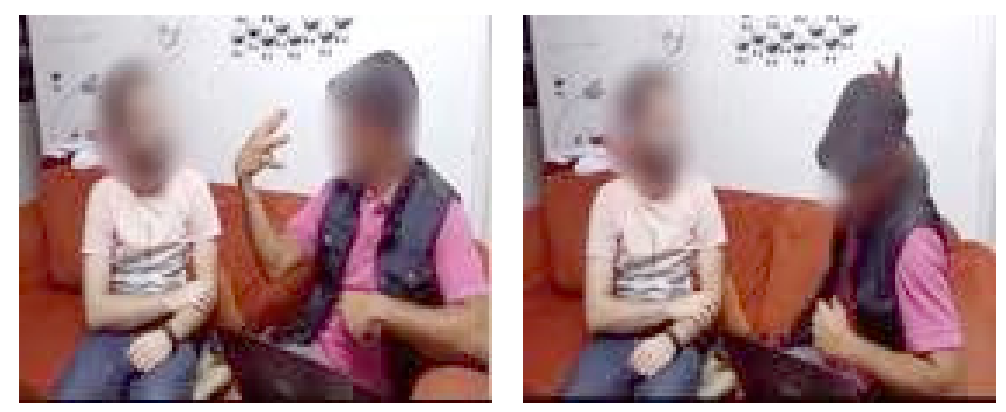

Figura 4. Participante realizando explicações sobre iluminação frontal e contra a luz. 
Em relação aos aspectos gramaticais e estruturas linguísticas da Libras, observamos que os alunos apresentam um conjunto ainda maior e mais diversificado de substantivos, verbos (incluindo verbos direcionais e não-direcionais), advérbios, adjetivos, pronomes interrogativos e conjunções, em enunciados estruturalmente mais complexos quando comparados aos realizados no primeiro vídeo (“Apresentação e Curso"). Há, inclusive, o uso de classificadores no momento em que um dos participantes está indicando o tremor no vídeo feito pelo colega (Fig. 5).

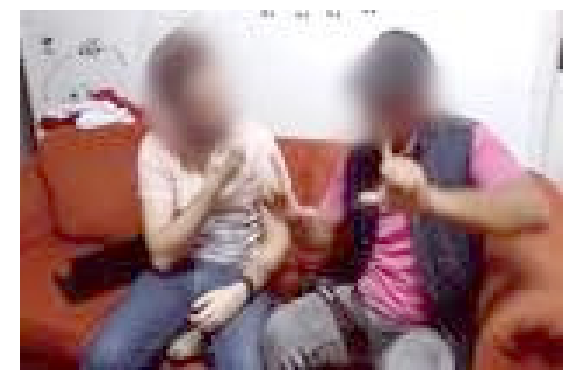

Figura 5. Classificador indicando tremor na sequência de vídeo.

Apesar de apresentar uma narrativa estruturalmente mais complexa que a realizada no primeiro material (vídeo "Apresentação e Curso"), chamamos a atenção para o fato de que, ao construírem "Trabalho de Libras", os aprendizes utilizam o recurso da redundância (GESSER, 2012), não na forma de repetição de sinais ou do conteúdo da fala, mas apresentando a repetição da ação dos personagens da narrativa da seguinte forma (ver Fig. 6):
a. Realização de filmagem da tarefa de Libras;
b. Apresentação da filmagem realizada ao colega;
c. Colega dá dicas para melhoria do material;
d. Realização de nova filmagem. 
As ações $\mathrm{A}, \mathrm{B}, \mathrm{C}$ e $\mathrm{D}$ se repetem ao longo do vídeo por cinco vezes, pois a narrativa se estrutura por meio da apresentação de uma situação-problema (Fig. 6 - A e B), que vai sendo resolvida por meio das idas e vindas do jovem, que reelabora seu trabalho em vídeo com base nas dicas e alterativas que seu colega apresenta (Fig. 6 - C e D). Essa forma de estruturação do material causa nos espectadores a ideia de humor, no entanto, não podemos deixar de marcar que isso também nos remete ao fato de que a redundância é uma estratégia utilizada por aprendizes indicando um nível ainda inicial da língua (cf. GESSER, 2012), que se reflete, no vídeo analisado, não no vocabulário ou nas estruturas gramaticais utilizadas, mas nas construções ao nível da estruturação textual.
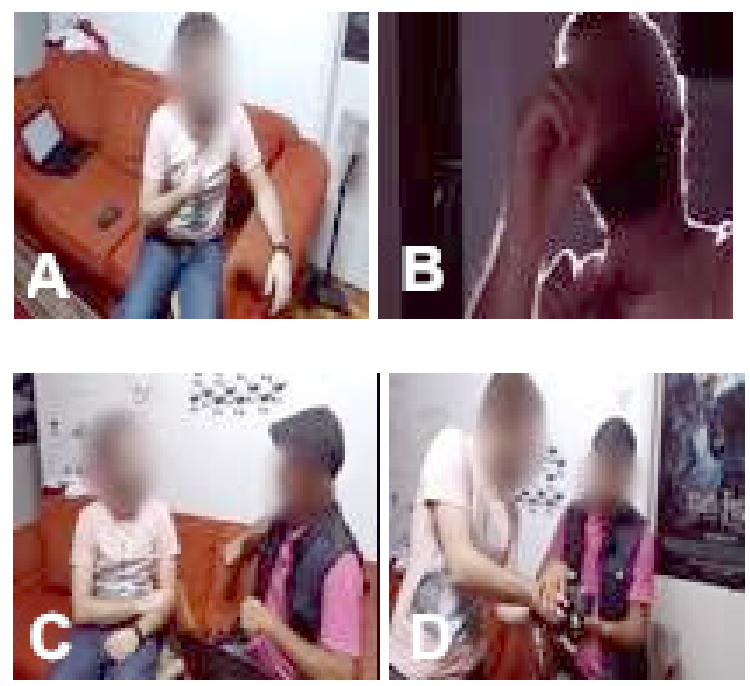

Figura 6. Vídeo "Trabalho de Libras": apresentação da situaçãoproblema (A e B), apresentação de dicas e alternativas para o problema da filmagem (C) e realização de nova filmagem (D). 
Essa observação não diminui a validade da afirmação feita anteriormente em relação à comparação desse segundo material com o primeiro, quando indicamos que houve o desenvolvimento dos alunos em relação aos aspectos linguísticos da Libras. Ao contrário disso, mostra que houve uma tentativa dos alunos em estruturar seus enunciados em um tipo textual mais elaborado do que o utilizado na primeira situação, levandoos, pelo contato prático com a língua ainda recente, a lançar mão dessa estratégia de repetição.

Cabe ressaltar que a apresentação em sala das narrativas em vídeo produzidas pelos alunos das disciplinas de Libras colaborou com a aquisição de novos conhecimentos linguísticos e textuais, ao mesmo tempo em que proporcionou a reelaboração de conhecimentos prévios, pelo próprio conteúdo dos vídeos, mas também pelas intervenções que as docentes e os outros alunos realizavam a fim de esclarecer, exemplificar e explicar conteúdos relacionados aos materiais narrativos.

Como mencionado anteriormente, a opção pela análise da estratégia pedagógica de produção de narrativas audiovisuais se deu pela percepção das autoras de que a experiência suscitava reflexões importantes para a temática do ensino de Libras como L2 para ouvintes. Nessa direção, entendemos que, para além do desenvolvimento de aspectos linguísticos, a realização das atividades em vídeo também possibilitou aos alunos a mobilização de conhecimentos acerca de aspectos sociais e políticos abordados durante as aulas, envolvidos com o fortalecimento linguístico da Libras e das pessoas surdas como parte de um grupo minoritário com características identitárias e culturais próprias. 


\section{O vídeo como possibilidade de reflexão sobre os aspectos sociais e políticos que envolvem a Libras}

Como evidenciado por Santos e Campos (2014), a disciplina de Libras deve propiciar ao aluno, além do ensino da própria língua, o contato com aspectos mais amplos a respeito do cenário da surdez, no sentido de promover uma reflexão sobre as formas de interação/comunicação mais adequadas junto aos surdos e a conscientização da diferença linguística em relação às pessoas ouvintes.

Nesse sentido, consideramos que os aspectos abordados ao longo da disciplina - temas como legislação, educação de surdos e formação de professores, questões teóricas relacionadas à história e à inclusão/exclusão dos surdos nas diversas esferas sociais, por exemplo - contribuíram para que os alunos adquirissem conhecimentos sobre aspectos sociais e políticos que envolvem a Libras e a surdez, atrelados ao conhecimento linguístico, como ilustraremos a seguir com o vídeo intitulado "Interação veterano e bixete", produzido por uma dupla de alunos do curso de Engenharia de Produção.

A narrativa apresenta um encontro entre uma aluna que acaba de ingressar na Universidade e seu colega veterano. Logo ao se encontrarem, o aluno a cumprimenta e ela responde (em Libras) que é surda. A partir de então, o diálogo se estabelece apenas em Libras, com o aluno respondendo que não haverá problemas para que conversem, já que ele estudou Libras no ano anterior.

É interessante notar que os alunos utilizaram o recurso da legenda em português escrito toda vez em que havia a interação entre eles através da fala oral (na figura 7, a seguir, a legenda pode ser observada na cena em que os jovens se encontram pela primeira vez), indicando uma atenção dos alunos na própria produção do vídeo, ao considerarem que, no caso dele ser assistido por uma pessoa surda, a legenda seria uma condição necessária. 

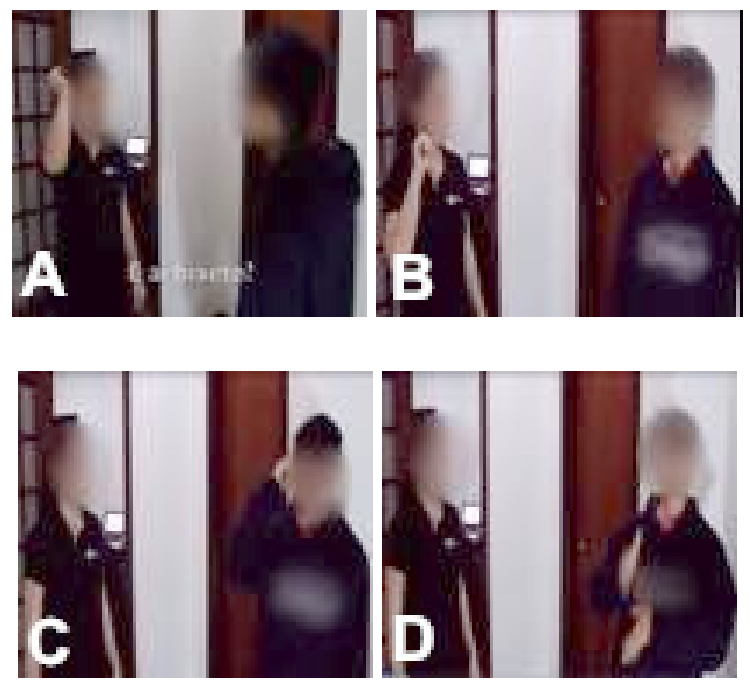

Figura 7: Sequência em que a aluna "bixete” (caloura) é recebida pelo veterano.

$\mathrm{Na}$ passagem da narrativa apresentada na Fig. 7, o aluno cumprimenta a colega (A) e ela sinaliza que não o compreende, pois é surda (B). Nos quadros seguintes, o aluno diz que a entendeu (C), pois fez o curso de Libras no ano passado (D). Essa passagem nos sugere que os alunos compreenderam que "as línguas de sinais são, [...] consideradas pela linguística como línguas naturais ou como um sistema linguístico legítimo e não como um problema do surdo ou como uma patologia da linguagem" (QUADROS e HEBERLE, 2006, p. 87), uma vez que buscaram demonstrar a importância do aprendizado da Libras para a convivência entre surdos e ouvintes, ao focalizar a interação através da língua de sinais como fundamental para o acolhimento da aluna surda pelo colega ouvinte - ambos comungando do mesmo espaço (universitário).

A importância da disciplina de Libras em relação aos aspectos sociais e políticos pode ainda ser observada em outra passagem da mesma 
narrativa, no momento em que um terceiro colega ouvinte se aproxima da dupla e os convida para sair e comer uma pizza (ver Fig.8 - A). Nesse momento, o aluno que cursou Libras atua como um intérprete para sua colega (Fig. 8 - B e C), ao pedir para que o amigo aguarde um minuto, pois vai convidá-la também.
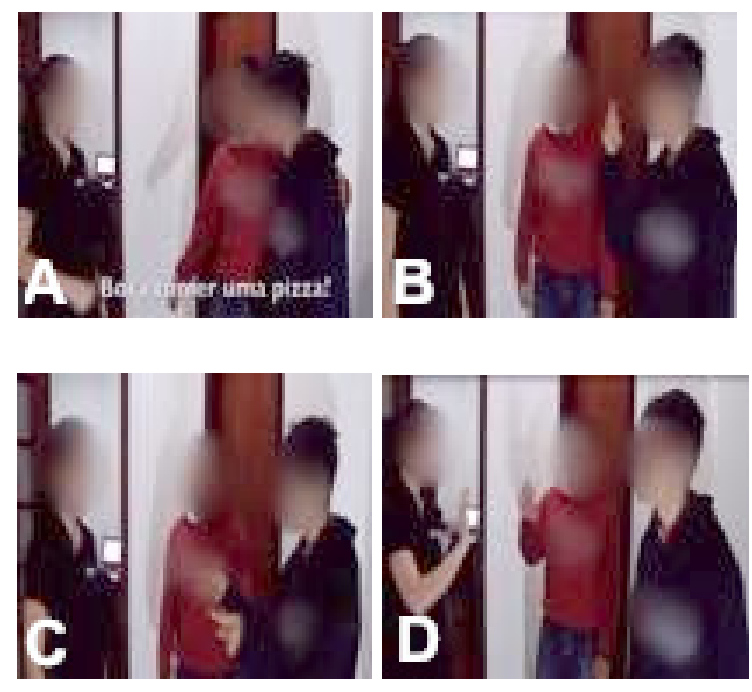

Figura 8: Sequência em que um terceiro colega ouvinte se aproxima.

A sequência apresentada na figura 8 ilustra como o momento de interpretação facilita, em seguida, a interação entre o ouvinte (que não cursou Libras) e a aluna surda (Fig. 8 - D). Ao realizar a interpretação do convite para a Libras, percebemos que os alunos compreenderam as possibilidades e responsabilidades da atuação do intérprete, entendido como aquele que é capaz de "viabilizar a comunicação entre surdos e ouvintes, atuando na fronteira entre os sentidos da língua oral (português) e da língua de sinais [...]" (KOTAKI e LACERDA, 2014, p. 206). O aluno 
que cursou Libras e que, portanto, tem um conhecimento básico da língua, demonstra estar envolvido na interação comunicativa (social e cultural) entre a colega surda e o amigo ouvinte, em um movimento que denota a sensibilização para a diferença linguística e a aceitação da Libras como uma língua natural, possível de circular nos diversos espaços sociais (na universidade, por exemplo), permitindo a acessibilidade necessária às pessoas surdas.

Em relação à narrativa, gostaríamos de salientar ainda que a escolha dos alunos por retratar um encontro casual com uma pessoa surda, um diálogo (no qual são abordados assuntos cotidianos) e um convite para jantar (ou seja, uma situação de interação social bastante comum), aponta para a compreensão de que a Libras constitui uma língua que é usada funcionalmente em diversos ambientes e contextos, refletindo a construção de um conceito de surdez bastante diferente daquele que pode ser observado no senso comum - como uma patologia, distúrbio ou doença, por exemplo.

Pudemos observar que o ensino da Libras como propomos, portanto, permitiu ao aluno "criar e narrar na nova língua [Libras], nas situações mais diversas” (SANTOS e CAMPOS, 2014, p. 248), mas também trazer à luz reflexões sobre as possibilidades de circulação da Libras como língua, de convivência entre surdos e ouvintes e da importância de uma formação (ao menos inicial) nas disciplinas de Libras que contemple a língua de sinais e também as discussões a respeito dos aspectos legais, históricos e políticos que são necessários para a promoção de acessibilidade na convivência entre surdos e ouvintes.

\section{Considerações finais}

O relato de experiência e as reflexões trazidas neste artigo constituem-se como parte de um movimento das autoras que - por 
considerarem, assim como aponta Gesser (2010, p. 47), que a prática profissional também é prática de construção de conhecimento por meio da qual o professor pensa e discute sobre seus próprios fazeres - buscaram refletir sobre os modos como organizaram/realizaram as estratégias pedagógicas para as disciplinas de Libras sob suas responsabilidades para fins de avaliação de suas práticas. Nesse movimento, portanto, pareceunos relevante compartilhar a experiência com as narrativas audiovisuais, no intuito de que ela possa colaborar com o desenvolvimento de uma compreensão do que significa ensinar Libras como L2.

Consideramos que a análise das três narrativas em vídeo apresentada neste artigo corrobora a escolha pela abordagem comunicativa para o ensino de Libras como L2, a partir da qual as situações didáticas foram pensadas de acordo com as funções que os alunos precisariam realizar na língua alvo, o que possibilitou a eles, em situações criadas no contexto de ensino e aprendizagem, o acesso aos conhecimentos específicos da língua, ao mesmo tempo em que fizeram o uso pragmático da mesma. Nesse processo, acreditamos na validade da proposta das narrativas audiovisuais como estratégia didática, por considerarmos serem uma alternativa às práticas usuais de uso descontextualizado da Libras em situações artificiais, como tratado por Albres (2012), ou de apresentação de sinais descontextualizados e "soltos", como evidenciado por Neves (2012).

O recurso de elaboração de narrativas possibilitou o envolvimento dos alunos na construção textual em Libras, o que mobilizou os conhecimentos linguísticos, políticos e sociais desenvolvidos ao longo das aulas.

Nas narrativas observamos a presença de sentenças em que aspectos como a noção temporal (presente, passado, futuro), a iconicidade e a simultaneidade foram explorados pelos alunos, que, diante das situações a serem narradas, tiveram a oportunidade de lançar hipóteses a respeito de novos vocabulários e construção de enunciados para a produção de sentidos nos discursos em Libras. As produções audiovisuais possibilitaram, ainda, 
que a tridimensionalidade da Libras em sua modalidade visual-gestual fosse um elemento contemplado e amplamente discutido ao longo das aulas, e esse movimento colaborou também para que, através das próprias narrativas, alunos e docentes pudessem ir contrastando as especificidades da língua-alvo (Libras) e da primeira língua (Português).

Para além da contribuição desta atividade pedagógica para aquisição de aspectos linguísticos da Libras, destacamos o papel fundamental que a atividade narrativa teve na ressignificação de noções sobre a pessoa surda e sobre o estatuto linguístico das línguas de sinais, contribuindo para o trabalho social e político, que também deve ser considerado objetivo das disciplinas de Libras.

Antes de finalizar, gostaríamos de destacar que, considerando as potencialidades dos recursos digitais para o desenvolvimento de propostas metodológicas para o ensino de Libras como L2, acreditamos que, assim como a experiência relatada, outras práticas que lancem mão dos recursos digitais podem ser bem sucedidas. A esse respeito, consideramos que o trabalho possa ter, futuramente, desdobramentos na busca por desenvolver narrativas de maneira coletiva e colaborativa, numa proposta que vai ao encontro do que Sevilla-Pávon e Maddalena (2015) denominaram de narrativas digitais: "breves filmes resultantes da prática de combinar múltiplos modos de tecnologia, como fotografias, texto, música, narração de voz e clips de vídeo para produzir uma narrativa" (SEVILLA-PAVÓN e MADDALENA, 2015, p. 225).

Desse modo, além da apresentação da história em Libras, os alunos poderiam, de maneira colaborativa, agregar ao vídeo outros recursos, como imagens, texto escrito em português, sons, trechos de outros vídeos, enfim, demais recursos que considerassem pertinentes para compor, em grupo, uma única narrativa. Alinhadas a Sevilla-Pávon e Maddalena (2015), acreditamos que essa maneira de realizar o trabalho com as narrativas digitais e o uso do recurso de videogravação ainda ofereceriam momentos mais descontraídos e mais propícios à aquisição de conteúdos (SEVILLA- 
PÁVON e MADDALENA, 2015), o que acreditamos contribuir para a apropriação de uma nova língua.

\section{Referências bibliográficas}

ALBRES, N. A. Ensino de Libras como segunda língua e as formas de registrar uma língua visuo-gestual: problematizando a questão. REVEL, v. 10, n. 19, 2012.

CAETANO, J. F.; LACERDA, C. B. F. Libras no currículo de cursos de licenciatura. In: LACERDA, C. B. F.; SANTOS, L. F. Tenho um aluno surdo, e agora? Introdução à Libras e educação de surdos. São Carlos: EdUFSCar, 2014.

CAMPOS, M. L. I. L. Educação inclusiva para surdos e as políticas vigentes. In: LACERDA, C. B. F.; SANTOS, L. F. Tenho um aluno surdo, e agora? Introdução à Libras e educação de surdos. São Carlos: EdUFSCar, 2014.

CARVALHO, D. J. Não basta SER SURDO para ser professor: as práticas que constituem o ser professor SURDO no espaço da inclusão. Dissertação de Mestrado em Educação, Universidade Federal do Espírito Santos, 149 f., 2016.

GESSER, A. Metodologia de Ensino em Libras como L2. Licenciatura e Bacharelado em Letras-Libras na Modalidade a Distância. Florianópolis: UFSC, 2010. Disponível em:<http:// www.libras.ufsc.br/colecaoLetrasLibras/eixoFormacaoPedagogico/ metodologiaDeEnsinoEmLibrasComoL2/assets/629/TEXTOBASE_ MEN_L2.pdf $>$. Último acesso em 30 set. 2016 
GESSER, A. O ouvinte e a surdez: sobre ensinar e aprender a Libras. São Paulo: Parábola Editorial, 2012.

KOTAKI, C. S.; LACERDA, C. B. F. O intérprete de Libras no contexto da escola inclusiva: focalizando sua atuação na segunda etapa do ensino fundamental. In: LACERDA, C. B. F.; SANTOS, L. F. Tenho um aluno surdo, e agora? Introdução à Libras e educação de surdos. São Carlos: EdUFSCar, 2014.

LEBEDEFF, T. B; SANTOS, A. N. Objetos de aprendizagem para o ensino de línguas: vídeos de curta-metragem e o ensino de Libras. RBLA. Belo Horizonte, v. 14, n. 4, p. 1073-1094, 2014.

LODI, A. C. B. Ensino da língua portuguesa como segunda língua para surdos: impacto na educação básica. In: LACERDA, C. B. F.; SANTOS, L. F. Tenho um aluno surdo, e agora? Introdução à Libras e educação de surdos. São Carlos: EdUFSCar, 2014.

MARTINEZ, P. Didática de línguas estrangeiras. São Paulo: Parábola Editorial, 2009.

NEVES, S. L. G. Um estudo dos recursos didáticos nas aulas de Língua Brasileira de Sinais para ouvintes. Anais Congresso TILS, 2012.

PEREIRA, M. C. P. A língua de sinais brasileira: análise de material didático de ensino como segunda língua para ouvintes. Linguasagem Revista Eletrônica de Popularização Científica em Ciências da Linguagem. São Paulo: Universidade Federal de São Carlos, 2009.

QUADROS, R. M.; HEBERLE, V. Curso de letras/licenciatura com habilitação em língua brasileira de sinais: inclusão nas universidades 
públicas brasileiras. In: BRASIL. Desafios da Educação à Distância na formação de professores. 1. Ed. Brasília: Ministério da Educação, 2006.

QUADROS, R. M. de; KARNOPP, L. Língua de sinais brasileira: estudos linguísticos. ArtMed: Porto Alegre, 2004.

SANTOS, L. F.; CAMPOS, M. L. I. L. O ensino de Libras para futuros professores da educação básica. In: LACERDA, C. B. F.; SANTOS, L. F. Tenho um aluno surdo, e agora? Introdução à Libras e educação de surdos. São Carlos: EdUFSCar, 2014.

SEVILLA-PÁVON, A.; MADDALENA, T. L. Aprendizagem de línguas com narrativas digitais: uma experiência no ensino do inglês para fins específicos. Revista Lugares de Educação [RLE], Bananeiras - PB, v. 5, n. 11, p. 255-267, Ago.-Dez., 2015. 